\title{
Adubação fosfatada na cultura do milho no nordeste paraense
}

\author{
Phosphorus fertilization in maize in northeastern of Pará state
}

\section{Eduardo Cézar Medeiros Saldanha*, Maria Eunice Lima da Rocha, José Leandro Silva de Araújo, José Darlon Nascimento Alves, Daiane de Cinque Mariano e Ricardo Shigueru Okumura}

Submissão: 07/08/2016 / Aceite: 22/05/2017

\section{RESUMO}

No Brasil, a cultura do milho (Zea mays L.) possui elevada produção, sendo que o Estado do Pará tem potencial para se tornar grande polo produtivo de grãos. Contudo, constitui-se de solos tropicais, os quais são ácidos e com baixa disponibilidade de fósforo. O objetivo do trabalho foi avaliar o crescimento e a produtividade de plantas de milho submetidas a diferentes doses de fósforo em Latossolo Amarelo no município de Capitão Poço, Nordeste do Estado do Pará, no ano de 2011. Na área experimental foi realizada a correção do solo por meio da calagem, visando-se aumentar a saturação por bases a $60 \%$. O delineamento experimental foi em blocos casualizados com quatro repetições, sendo os tratamentos empregados: $0 ; 45 ; 90 ; 135$ e $180 \mathrm{~kg} \mathrm{ha}^{-1}$ de $\mathrm{P}_{2} \mathrm{O}_{5}$, aplicados no sulco de semeadura, utilizando a fonte superfosfato triplo $\left(46 \%\right.$ de $\left.\mathrm{P}_{2} \mathrm{O}_{5}\right)$. As variáveis altura da planta, diâmetro do colmo, número de folhas e número de espigas apresentaram melhor ajuste da equação quadrática à aplicação de $\mathrm{P}_{2} \mathrm{O}_{5}$ no sulco de semeadura com a máxima eficiência técnica obtida nas doses de 142,1 $\mathrm{kg} \mathrm{ha}^{-1} ; 114,62 \mathrm{~kg} \mathrm{ha}^{-1} ; 130,59 \mathrm{~kg} \mathrm{ha}^{-1} \mathrm{e}$ $145 \mathrm{~kg} \mathrm{ha}^{-1}$ de $\mathrm{P}_{2} \mathrm{O}_{5}$, respectivamente. A aplicação de $179,87 \mathrm{~kg} \mathrm{ha}^{-1}$ de $\mathrm{P}_{2} \mathrm{O}_{5}$ na cultura do milho, variedade BR 5102, em Latossolo Amarelo distrófico típico, proporcionou a produtividade de $6,58 \mathrm{t} \mathrm{ha}^{-1}$ de grãos, nas condições edafoclimáticas da região de Capitão Poço.

PALAVRAS-CHAVE: Zea mays L., fertilidade do solo, Latossolo Amarelo, Amazônia Oriental.

\section{ABSTRACT \\ In Brazil, the maize crop has high production volume, and the State of Pará has the potential to become major center for grain production. However, it consists of \\ Universidade Federal Rural da Amazônia, Capitão Poço, PA, Brasil. \\ *Autor para correspondência <ecmsaldanha@yahoo.com.br>}

tropical soils, which are acidic and low phosphorus availability. The aims of this study was to evaluate the growth and productivity of maize plants exposed to different rates of phosphorus in typical dystrophic Yellow Latosol in Capitão Poço city, Northeastern Pará State, in 2011. In the experimental area, soil correction was performed by liming, increasing the base saturation to $60 \%$. The experimental design was a randomized block with four replicates, in which the treatments were: $0 ; 45 ; 90 ; 135$ and $180 \mathrm{~kg} \mathrm{ha}^{-1}$ of $\mathrm{P}_{2} \mathrm{O}_{5}$ applied at sowing, using triple superphosphate source $\left(46 \% \quad \mathrm{P}_{2} \mathrm{O}_{5}\right)$. The variables: plant height, stem diameter, number of leaves and number of ears showed a better adjustment of quadratic equation to application of $\mathrm{P}_{2} \mathrm{O}_{5}$ in sowing furrow with maximum technical efficiency obtained at rates of $142.1 \mathrm{~kg} \mathrm{ha}^{-1}$; $114.62 \mathrm{~kg} \mathrm{ha}^{-1} ; 130.59 \mathrm{~kg} \mathrm{ha}^{-1}$ and $145 \mathrm{~kg} \mathrm{ha}^{-1}$ of $\mathrm{P}_{2} \mathrm{O}_{5}$, respectively. The application of $179.87 \mathrm{~kg} \mathrm{ha}^{-1}$ of $\mathrm{v}$ in corn crop (BR 5102 variety) in a typical dystrophic Yellow Latosol promoted yield of $6.58 \mathrm{tha}^{-1}$ of grains under the soil and climatic conditions of Capitão Poço region.

KEYWORDS: Zea mays L., soil fertility, yellow Oxisol, Eastern Amazon.

\section{INTRODUÇÃO}

No Brasil, a cultura do milho possui alto potencial produtivo, alcançando produtividades de até $10 \mathrm{t} \mathrm{ha}^{-1}$ de grãos, em condições experimentais e/ ou por agricultores que adotam tecnologias adequadas (CARVALHO et al. 2004). Com relação à Região Norte do país, o Estado do Pará tem destaque na produção de grãos, onde a área colhida na safra 2011/2012 foi de 236,3 mil hectares e uma produção de 599,7 mil toneladas e produtividade média de $2.538 \mathrm{~kg} \mathrm{ha}^{-1}$, com destaque para os municípios de Paragominas, Dom Eliseu e São Félix do Xingu (IDESP 2011). As 
classes dos Latossolos e Argissolos constituem mais de $70 \%$ dos solos da região amazônica (UCHÔA et al. 2009).

Nessas áreas predominam, como na maioria dos solos brasileiros, solos altamente intemperizados e, de modo geral, deficiente em $\mathrm{P}$, apresentando alta capacidade de retenção desse nutriente, resultando em formas pouco disponíveis às plantas (NOVAIS et al. 2007). Além disso, os solos tropicais são na sua maioria ácidos e com baixa disponibilidade de fósforo, o que constitui um fator limitante de produção (FERNANDES et al. 2013). As baixas fertilidades dos solos paraenses são um empecilho para a obtenção de elevadas produtividades na região, uma vez que, de acordo com BASTOS et al. (2010), plantas de desenvolvimento intenso e de ciclo curto, como o milho, requerem maior nível de fósforo em solução e reposição mais rápida do $\mathrm{P}$-adsorvido comparada às plantas perenes. A principal forma que o íon fosfato atinge a região da rizosfera é por meio do processo de difusão, o qual é caracterizado por apresentar valores muito baixos.

A importância do P na planta é decorrente, dentre outras, das suas funções em promover a formação e o crescimento de raízes (ALMEIDA JUNIOR et al. 2009). Nesse sentido, esse trabalho teve como objetivo avaliar o crescimento e a produtividade do milho, submetido a doses de fósforo em Latossolo Amarelo no Nordeste do Estado do Pará.

\section{MATERIAL E MÉTODOS}

O experimento foi conduzido em área experimental da Universidade Federal Rural da Amazônia - UFRA, Campus de Capitão Poço, Estado do Pará, no período de setembro a dezembro de 2011. A caracterização química e física do solo realizada antes da instalação do experimento apresentou os seguintes resultados: $\mathrm{pH}\left(\mathrm{H}_{2} \mathrm{O}\right)=5,1 ; \mathrm{MO}=18 \mathrm{~g}$ $\mathrm{kg}^{-1} ; \mathrm{P}\left(\right.$ Mehlich 1) $=1,3 \mathrm{mg} \mathrm{dm}{ }^{-3} ; \mathrm{Ca}^{2+}=1,1 \mathrm{cmol}_{\mathrm{c}}$ $\mathrm{dm}^{-3} ; \mathrm{Ca}^{2+}+\mathrm{Mg}^{2+}=1,4 \mathrm{cmol}_{\mathrm{c}} \mathrm{dm}^{-3} ; \mathrm{K}=0,05 \mathrm{cmol}_{\mathrm{c}}$ $\mathrm{dm}^{-3} ; \mathrm{H}+\mathrm{Al}^{3+}=3,2 \mathrm{cmol} \mathrm{dm}^{-3} ; \mathrm{Al}^{3+}=0,3 \mathrm{cmol}_{\mathrm{c}} \mathrm{dm}^{-3}$; $\mathrm{CTC}=4,61 \mathrm{cmol}_{\mathrm{c}} \mathrm{dm}^{-3} ; \mathrm{V} \%=30,6 \% ; \mathrm{m} \%=25,8 \%$. A análise granulométrica apresentou valores de: areia $=$ $733 \mathrm{~g} \mathrm{~kg}^{-1}$; argila $=177 \mathrm{~g} \mathrm{~kg}^{-1}$ e silte $=90 \mathrm{~g} \mathrm{~kg}^{-1}$, o que caracteriza textura franco-arenosa. $\mathrm{O}$ solo da região é classificado como Latossolo Amarelo distrófico (EMBRAPA 2013). Com base na análise química do solo foi realizada a correção por meio da calagem, visando aumentar a saturação por bases a $60 \%$.
O clima da região enquadra-se nos tipos climáticos Ami, da classificação de Köppen, caracterizado como chuvoso, apresentando, porém, pequena estação seca que historicamente ocorre nos meses de setembro, outubro, novembro e dezembro. A temperatura média situa-se em torno de $26,2{ }^{\circ} \mathrm{C}$, enquanto a umidade relativa fica em torno de $83 \%$ (PACHECO \& BASTOS 2002). Os dados de precipitação pluviométrica e temperatura do ar ocorridos durante o período de condução do experimento estão apresentados na Figura 1.

A variedade de milho utilizada foi a BR 5102 , de porte mediano, grãos alaranjados e textura do endosperma semidentado. $\mathrm{O}$ delineamento experimental foi em blocos casualizados com quatro repetições. As parcelas experimentais foram constituídas de cinco linhas de 4,0 m espaçadas de $0,8 \mathrm{~m} \times 0,2 \mathrm{~m}$, correspondendo a 62.500 plantas ha $^{-1}$. A parcela útil foi composta por 10 plantas distribuídas nas três linhas centrais, coletadas aleatoriamente, descontando $0,5 \mathrm{~m}$ de cada extremidade destas linhas.

O sistema de plantio adotado foi o convencional, na qual o preparo da área foi mecanizado, constituindose de gradagem aradora. A semeadura foi efetuada manualmente, utilizando-se três sementes por cova, e aos 17 dias após a emergência (DAE), foi feito o desbaste, deixando-se uma planta por cova. Os tratamentos empregados foram: $0 ; 45 ; 90 ; 135$ e 180 $\mathrm{kg} \mathrm{ha}^{-1}$ de $\mathrm{P}_{2} \mathrm{O}_{5}$, utilizou-se a fonte superfosfato triplo $\left(46 \%\right.$ de $\left.\mathrm{P}_{2} \mathrm{O}_{5}\right)$, aplicando-se na linha de plantio.

As adubações nitrogenadas e potássicas foram parceladas em três aplicações, sendo $1 / 3$ da dose no sulco de semeadura e $2 / 3$ restantes divididos em duas aplicações de cobertura, realizadas no estádio fenológico V6 e V10 da cultura (RITCHIE et al. 1993). As doses totais empregadas foram $80 \mathrm{~kg} \mathrm{ha}^{-1}$ de $\mathrm{N}$, com a fonte sulfato de amônio $(21 \%$ de $\mathrm{N})$ e $60 \mathrm{~kg} \mathrm{ha}^{-1}$ de $\mathrm{K}_{2} \mathrm{O}$, cloreto de potássio $\left(60 \%\right.$ de $\left.\mathrm{K}_{2} \mathrm{O}\right)$, conforme recomendado por CRAVO et al. (2007). Além disso, foi realizada uma complementação nutricional com duas aplicações de nutrientes foliares, de forma preventiva, visando o fornecimento dos micronutrientes boro (dose de $2 \mathrm{~kg} \mathrm{ha}^{-1}$ de B, utilizando a fonte ácido bórico) e zinco (dose de $4 \mathrm{~kg}$ $\mathrm{ha}^{-1}$ de $\mathrm{Zn}$, utilizando a fonte sulfato de zinco).

As avaliações constaram das seguintes variáveis: altura da planta (AP), medida desde a superfície do solo até a inserção da folha bandeira; diâmetro basal do colmo (DC), tomando como base a região do colo da planta ( $\pm 5 \mathrm{~cm}$ de altura); e número 


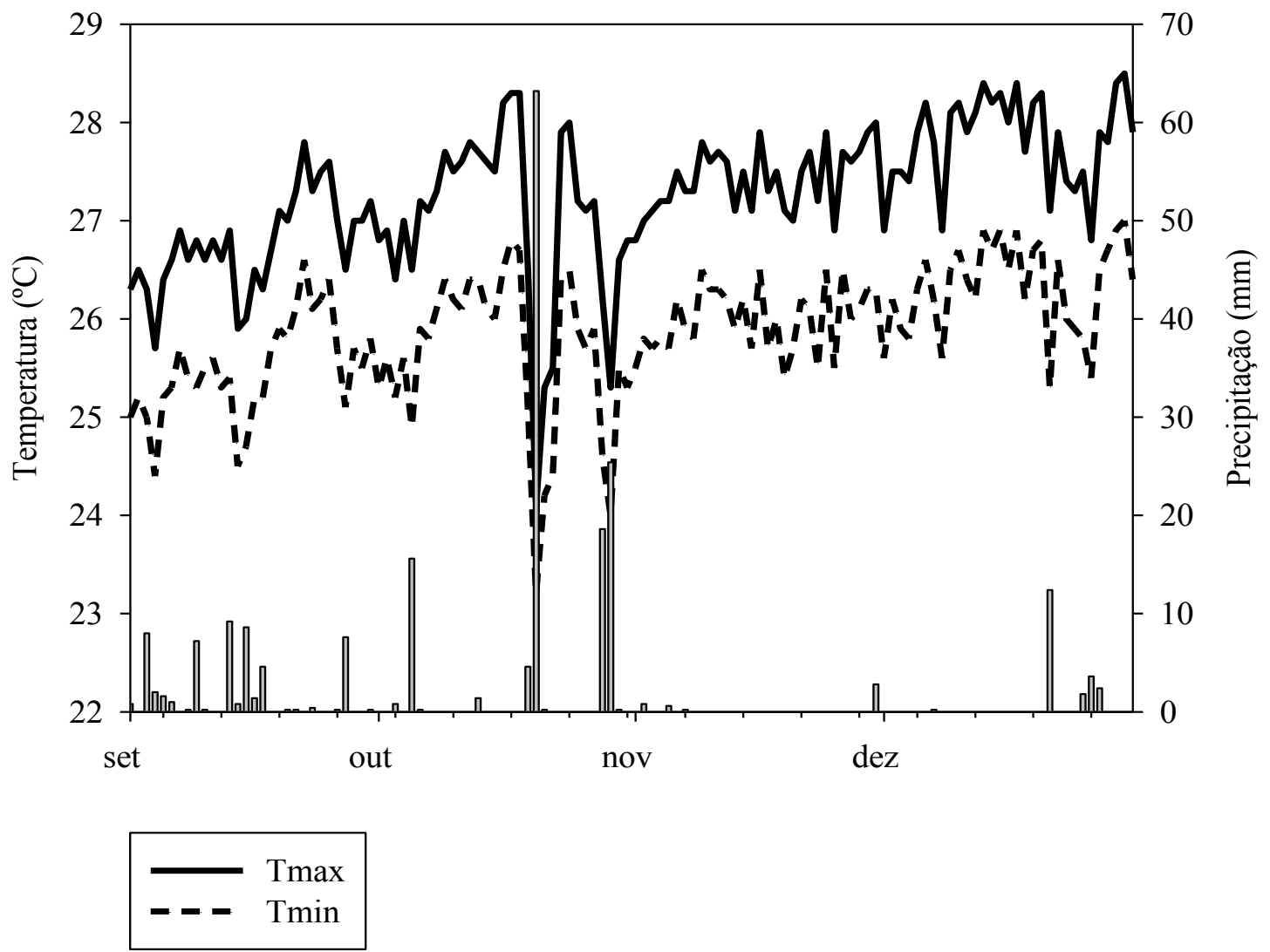

Figura 1. Precipitação pluviométrica e temperatura do ar durante o desenvolvimento da cultura do milho no município de Capitão Poço, PA.

Figure 1. Rainfall and air temperature during the corn development in Capitão Poço city, of Pará State, Brazil.

de folhas por planta (NF), realizados aos 41 DAE. Aos 81 DAE foram avaliados o número de espigas por planta (EP); produção de matéria seca, onde materiais colhidos referentes à matéria fresca foram colocados para secar em estufa com circulação forçada de ar a $65{ }^{\circ} \mathrm{C}$ por 72 horas e extrapolado, posteriormente, para toneladas por hectare e produtividade de grãos em três linhas centrais de cada parcela, tendo-se determinado a massa dos grãos colhidos, extrapolados para toneladas por hectares, a $13 \%$ de umidade.

Inicialmente, verificou-se a normalidade e homocedasticidade residuais dos dados experimentais ( $p>0,01)$ pelos testes de Shapiro-Wilk e de Levene, respectivamente, mediante emprego do software estatístico SAS (SAS 2008). Posteriormente, atendidas as pressuposições básicas, realizou-se a análise de regressão polinomial, observando-se os resultados do teste $\mathrm{F}(\mathrm{p}<0,05)$ da análise de variância e do teste $t$ de Student $(p<0,05)$, para os coeficientes de determinação, por meio do software estatístico Sisvar (FERREIRA 2011).

\section{RESULTADOS E DISCUSSÃO}

As variáveis respostas analisadas AP, DC, NF, NE, MS e produtividade foram influenciados pelas doses de P (Tabela 1), mostrando efeito significativo dos tratamentos $(\mathrm{p}<0,05)$.

Aaltura da planta apresentou resposta quadrática às doses de $\mathrm{P}_{2} \mathrm{O}_{5}$, cujo coeficiente de determinação explica que o efeito dos tratamentos com $\mathrm{P}$ sobre a variável analisada foi da ordem de $98 \%$ (Figura 2A) e que, a melhor resposta $(1,42 \mathrm{~m})$, é alcançada com a dose de $142,1 \mathrm{~kg} \mathrm{ha}^{-1}$ de $\mathrm{P}_{2} \mathrm{O}_{5}$. LUCENA et al. (2000), usando um intervalo de doses $(0 ; 120 ; 180$ e $240 \mathrm{~kg} \mathrm{ha}^{-1}$ ) de $\mathrm{P}_{2} \mathrm{O}_{5}$, na fonte de superfosfato triplo, em condições de campo, em Latossolo Vermelho Amarelo distrófico, verificaram altura máxima de $151,2 \mathrm{~cm}$, quando aplicado a dose de $177,3 \mathrm{~kg} \mathrm{ha}^{-1} \mathrm{de}$ $\mathrm{P}_{2} \mathrm{O}_{5}$, o que reforça os resultados obtidos no presente estudo.

HARGER et al. (2007), avaliando o efeito de duas fontes (superfosfato triplo e fosfato natural reativo de Arad) e quatro doses de fósforo no 
Tabela 1. Análise de variância para as características altura da planta (AP), diâmetro do colmo (DC), número de folhas (NF), número de espigas (NE), massa de matéria seca (MS) e produtividade de grãos de milho (PROD), cultivar BR 5102, cultivadas com diferentes doses de $\mathrm{P}_{2} \mathrm{O}_{5}$, em Latossolo Amarelo. Capitão Poço, PA.

Table 1. Analysis of variance for plant height (AP), stem diameter (DC), number of leaves (NF), number of ears (NE), dry matter (MS) and corn yield (PROD), cultivar BR 5102, cultivated with different doses of $\mathrm{P}_{2} \mathrm{O}_{5}$ in Oxisoil. Capitão Poço city, of Pará State, Brazil.

\begin{tabular}{|c|c|c|c|c|c|c|c|}
\hline \multirow{2}{*}{$\begin{array}{l}\text { Fonte } \\
\text { Variação }\end{array}$} & \multirow[t]{2}{*}{ GL } & \multicolumn{6}{|c|}{ Quadrados médios } \\
\hline & & AP & $\mathrm{DC}$ & NF & $\mathrm{NE}$ & MS & PROD \\
\hline Doses & 4 & $0,408^{* *}$ & $0,472^{* *}$ & $5,696^{* *}$ & $0,140^{*}$ & $29,575^{*}$ & $9,961^{* *}$ \\
\hline Bloco & 3 & $0,009^{\text {n.s. }}$ & $0,068^{\text {n.s. }}$ & $0,342^{\text {n.s. }}$ & $0,004^{\text {n.s. }}$ & $40,450^{* *}$ & $0,398^{\text {n.s. }}$ \\
\hline Resíduo & 12 & 0,021 & 0,023 & 0,525 & 0,029 & 6,075 & 0,830 \\
\hline CV (\%) & & 12,30 & 8,98 & 7,25 & 23,20 & 18,74 & 25,77 \\
\hline Média geral & & 1,16 & 1,68 & 9,99 & 0,745 & 13,15 & 3,537 \\
\hline
\end{tabular}

crescimento inicial do milho, afirmaram que os teores de P no limbo foliar e parte aérea das plantas de milho sempre foram maiores quando se utilizou o superfosfato triplo, indicando a melhor nutrição da planta com o uso de fonte de alta solubilidade, por estar diretamente associado à maior velocidade de liberação do nutriente pelo fosfato solúvel, e uma diminuição do efeito da competição solo/planta, uma vez que a fixação do fósforo pelos colóides do solo ocorre de forma preferencial.

Para o diâmetro do colmo, os dados obtidos se ajustaram a uma função quadrática, com coeficiente de determinação $(\mathrm{R} 2=0,98)$, mostrando que a função possui boa capacidade preditiva (Figura 2B). Nas condições testadas, a dose $114,62 \mathrm{~kg} \mathrm{ha}^{-1}$ de $\mathrm{P}_{2} \mathrm{O}_{5}$ proporcionou diâmetro máximo do colmo de 1,98 $\mathrm{cm}$, variável importante na avaliação de genótipos de milho em programas de melhoramento, por ser medida da resistência ao acamamento (GOMES et al. 2010). Além disso, MAGALHÃES et al. (1995) reforçam a importância do colmo do milho como suporte de folhas e partes florais, assim como órgão de reserva no acúmulo de sacarose.

O número de folhas em função das doses de $\mathrm{P}_{2} \mathrm{O}_{5}$ apresentou aumento em função do incremento das doses (Figura 2C), com o número máximo de folhas obtido na dose de $130,59 \mathrm{~kg} \mathrm{ha}^{-1}$ de $\mathrm{P}_{2} \mathrm{O}_{5}$. A partir dessa dose há uma tendência decrescente do número de folhas produzidas pela cultura do milho. Uma das principais funções do fósforo na planta, como integrante da molécula do ATP, é atuar no armazenamento e na transferência da energia química captada da luz solar na fotossíntese. Dessa forma, o desenvolvimento da parte aérea é influenciado pela quantidade de fósforo absorvido. O número de folhas, assim como a área foliar na planta de milho, têm sido reportados na literatura (MAGALHÃES et al. 1995, ALVIM et al. 2010) como variáveis de influência direta na produtividade de grãos em respostas a disponibilidade de nutrientes.

Com relação ao número de espigas, por ocasião da colheita, apresentou comportamento quadrático com coeficiente de determinação na ordem de $95 \%$ (Figura 3A). A expressão do ponto máximo $(y=1,22)$ é alcançada com a dose de $145 \mathrm{~kg} \mathrm{ha}^{-1}$ de $\mathrm{P}_{2} \mathrm{O}_{5}$, e a partir desta, não houve mais resposta. A obtenção do maior número de grãos possível é função da população e do número de espigas encontradas por planta e por área, os quais variam com o tipo de híbrido utilizado (LOPES et al. 2007). Assim, um determinado número de espigas produtivas resulta do número de plantas emergidas e do número de espigas potenciais (CALADO et al. 2008).

Para a produção de matéria seca da parte aérea, os dados se ajustaram a uma função linear, indicando, que para essa variável, o intervalo de doses não possibilitou a indicação de uma dose em função do ponto máximo, ou seja, as doses testadas não possibilitaram a máxima produção de matéria seca nas condições edafoclimáticas do experimento (Figura 3B). 

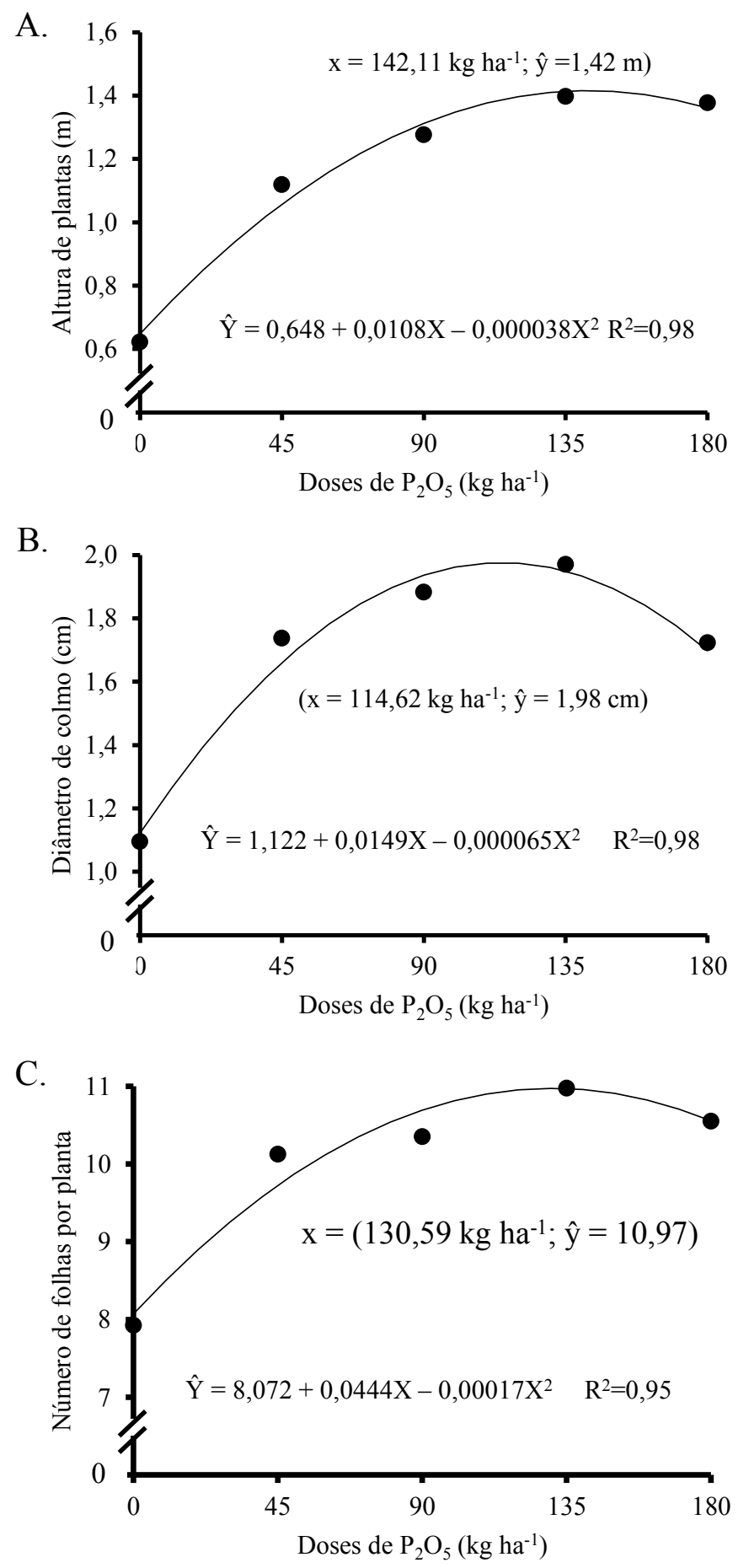

Figura 2. (A) Altura da planta (m), (B) diâmetro do colmo (cm) e (C) número de folhas por planta de plantas de milho em resposta a doses de $\mathrm{P}_{2} \mathrm{O}_{5}$, em um Latossolo Amarelo do nordeste paraense.

Figure 2.The plant height (A), stem diameter (B) and number of leaves (C) of corn plants in response the doses of $\mathrm{P}_{2} \mathrm{O}_{5}$, in a Oxisol in northeastern of Pará State. 

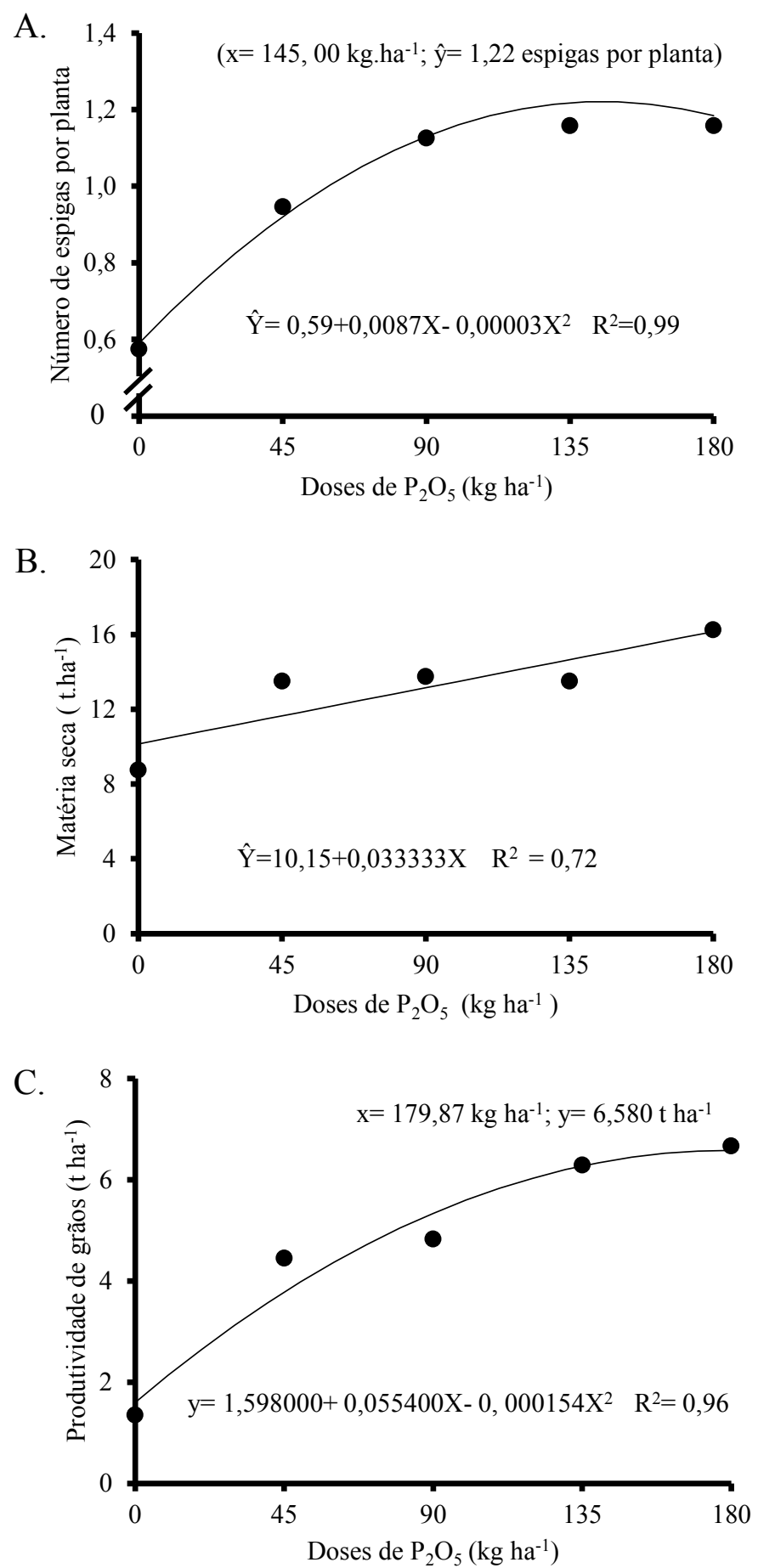

Figura 3. (A) Número de espigas por planta, (B) produção de matéria seca da parte aérea (t ha-1) e (C) produtividade de grãos $\left(\mathrm{t} \mathrm{ha}^{-1}\right)$ de plantas de milho em resposta a doses de $\mathrm{P}_{2} \mathrm{O}_{5}$, em um Latossolo Amarelo do nordeste paraense.

Figure 3. The number of ears (A), dry matter production of the aerial part (B) and grain yield (C) of corn plants in response the doses of $\mathrm{P}_{2} \mathrm{O}_{5}$, in a Oxisol in northeastern of Pará State. 
BASTOS et al. (2010) verificando o efeito de doses de $\mathrm{P}$ recomendadas em função da capacidade máxima de adsorção de fósforo - CMAP (\%), na cultura do milho, em seis classes de solos do Estado de Alagoas, observaram que o aumento da dose de fósforo no solo promoveu incremento na concentração do elemento na parte aérea. Para MIOLA et al. (1999) a tendência de linearidade do aumento de matéria seca da parte aérea das plantas pode ser indicativa de que outros fatores do solo pouco interferiram na resposta das plantas à adubação fosfatada.

Com relação à produtividade (Figura 3C), observou-se comportamento quadrático com coeficiente de determinação na ordem de 96\%, onde a expressão do ponto máximo da planta $(\mathrm{y}=$ $6,58 \mathrm{t} \mathrm{ha}^{-1}$ ) seria com a dose de $179,87 \mathrm{~kg} \mathrm{ha}^{-1}$ de $\mathrm{P}_{2} \mathrm{O}_{5}$. SOUZA et al. (2011), avaliando diferentes fontes fosfatadas e quantificando o $\mathrm{P}$ extraído em Latossolos com diferentes texturas (média, argilosa e muito argilosa), em condições de vaso, encontraram aumento do conteúdo de $\mathrm{P}$ no tecido vegetal, em Latossolo Amarelo com textura média, justificando esse resultado em virtude da presença de menores quantidades de argila, o que pode ter contribuído para a boa resposta do milho às doses aplicadas neste estudo. LUCENA et al. (2000), usando um intervalo de doses $\left(0 ; 120 ; 180\right.$ e $\left.240 \mathrm{~kg} \mathrm{ha}^{-1}\right)$ de $\mathrm{P}_{2} \mathrm{O}_{5}$, com a fonte de superfosfato triplo, em condições de campo, em Latossolo Vermelho Amarelo distrófico, obtiveram um rendimento de grãos de $2.258,2 \mathrm{~kg} \mathrm{ha}^{-1}$ quando a dose foi no nível de $197,6 \mathrm{~kg} \mathrm{ha}^{-1}$ de $\mathrm{P}_{2} \mathrm{O}_{5}$, podendose observar uma proximidade aos intervalos de doses utilizados neste trabalho.

\section{CONCLUSÕES}

As variáveis altura da planta, diâmetro do colmo, número de folhas por planta, número de espigas por planta, matéria seca da planta e produtividade de grãos para a variedade de milho BR 5102, em Latossolo Amarelo distrófico típico, no município de Capitão Poço, apresentaram respostas positivas e significativas à aplicação de $\mathrm{P}_{2} \mathrm{O}_{5}$ no sulco de semeadura.

A aplicação de $179,87 \mathrm{~kg} \mathrm{ha}^{-1}$ de fósforo $\left(\mathrm{P}_{2} \mathrm{O}_{5}\right)$ na cultura do milho proporcionou a produtividade de $6,58 \mathrm{t} \mathrm{ha}^{-1}$ de grãos.

\section{REFERÊNCIAS}

ALMEIDA JÚNIOR AB et al. 2009. Efeito de doses de fósforo no desenvolvimento inicial da mamoneira. Revista Caatinga 22: 217-221.

ALVIM KRT et al. 2010. Quantificação da área foliar e efeito da desfolha em componentes de produção de milho. Ciência Rural 40: 1017-1022.

BASTOS AL et al. 2010. Resposta do milho a doses de fósforo. Revista Brasileira de Engenharia Agrícola e Ambiental 14: 485-491.

CALADO JMG et al. 2008. Componentes da produção de grão em genótipos de trigo mole nas condições mediterrânicas. Revista de Ciências Agrárias 31: 68-78.

CARVALHO MAC et al. 2004. Produtividade do milho em sucessão a adubos verdes no sistema de plantio direto e convencional. Pesquisa Agropecuária Brasileira 39: 47-53. CRAVO MS et al. 2007. Recomendações de adubação e calagem para o Estado do Pará. Belém: Embrapa Amazônia Oriental. 262p.

EMBRAPA - Empresa Brasileira de Pesquisa Agropecuária. 2013. Sistema brasileiro de classificação de solos. Brasília: Embrapa. 353p.

FERNANDES AR et al. 2013. Produtividade de feijão caupi em função da calagem e fósforo. Revista Caatinga 26: 54-62.

FERREIRA DF. 2011. Sisvar: a computer statistical analysis system. Ciência e Agrotecnologia 35: 1039-1042.

GOMES LS et al. 2010. Resistência ao acamamento de plantas e ao quebramento do colmo em milho tropical. Pesquisa Agropecuária Brasileira 45: 140-145.

HARGER N et al. 2007. Avaliação de fontes e doses de fósforo no crescimento inicial do milho. Semina: Ciências Agrárias 28: 39-44.

IDESP - Instituto de Desenvolvimento Econômico, Social e Ambiental do Pará. 2011. Boletim Produção Agrícola do Pará.

LOPES SJ et al. 2007. Relações de causa e efeito em espigas de milho relacionadas aos tipos de híbridos. Ciência Rural 37: 1536-1542.

LUCENA LFC et al. 2000. Resposta do milho a diferentes dosagens de nitrogênio e fósforo aplicados ao solo. Revista Brasileira de Engenharia Agrícola e Ambiental 4: 334-337. MAGALHÃES PC et al. 1995. Fisiologia da planta de milho. Sete Lagoas: Embrapa - CNPMS. 27p. (Circular Técnica, 20).

MIOLA GR et al. 1999. Avaliação da disponibilidade de fósforo no solo para a cultura do milho. Pesquisa Agropecuária Brasileira 34: 813-819.

NOVAIS RF et al. 2007. Fósforo. In: NOVAIS RF et al. (Eds.). Fertilidade do solo. Viçosa: Sociedade Brasileira de Ciência do Solo. p.471-550.

PACHECO NA \& BASTOS TX. 2002. Análise frequencial da chuva em Capitão Poço, PA. Belém: Embrapa Amazônia Oriental. 16p. (Documentos, 133).

RITCHIE SW et al. 1993. How a corn plant develops. Ames: Iowa State University of Science and Technology/ Cooperative Extension Service. 26p. (Special Report, 48). 
SAS. 2008. SAS/STAT ${ }^{\circledR} 9.2$ User's guide. Version 9.2, Cary, NC: SAS Institute Inc. 584p.

SOUZA CHE et al. 2011. Extratores para fósforo disponível em Latossolos e eficiência de fontes fosfatadas para milho cultivado em vaso. Revista Brasileira de Milho e Sorgo 10: 38-46.

UCHÔA SCP et al. 2009. Fertilidade do solo. In: ZILLI JE et al. (Eds.). A Cultura do feijão-caupi na Amazônia Brasileira. Boa Vista: Embrapa. p.132-183. 